\title{
The use of the ICF-CY for describing dynamic functioning profiles: outcomes of a teacher training programme applied in Portugal
}

\author{
Manuela Sanches-Ferreira, Pedro Lopes-dos-Santos, Sílvia Alves \\ \& Mónica Silveira-Maia
}

\begin{abstract}
In keeping with the international trend towards inclusive education and a contextsensitive approach to students' needs, Portugal enacted, in 2008, a law that stipulated the use of the International Classification of Functioning, Disability and Health for Children and Youth (ICF-CY) to inform special needs assessment and eligibility procedures. The necessity of conceptual and practical adjustments in the use of the ICF-CY brings up the need for training programmes that can properly prepare regular and special education teachers. This paper examines the impact of an in-service training for teachers on using the ICF-CY for describing the functioning profiles of students supported by special education services. A 25-hour in-service training was developed focusing on the biopsychosocial and person-environment fit perspectives of the ICF-CY framework. To evaluate the effects of training, 236 descriptions of functioning profiles - produced before and after the in-service training - were compared. Results showed that the model adopted in the in-service teacher training course contributed to the enhancement of teachers' skills in describing more comprehensive functioning profiles of students, reflecting a dynamic perspective among the ICF-CY components. Specifically, teachers were more able to describe the impact of the environment on student's functioning, identifying facilitators and barriers that may inform the definition of strategies in Individualized Education Programs.
\end{abstract}




\section{KEYWORDS}

Educational policy; assessment; ICF-CY; Individualized Educational Programs; students with additional support needs

\section{Introduction}

Over the past few decades, inclusion became a prominent issue in educational thinking and practices. Prompted by the Salamanca Statement (UNESCO 1994) and sustained by several international treaties (e.g. UN 1989; UN 2006), current education policies stress the need to respect and preserve the right of all children to an equitable quality edu- cation, including those who have disabilities. Thus, educational issues are now focused on the purpose of developing a school for all, in which the diversity of students should be successfully addressed in mainstream settings (European Agency for Special Needs and Inclusive Education 2011; Sanches-Ferreira 2007).

Learners with disabilities experience significant barriers regarding their engagement and participation in regular school activities (WHO 2011). Therefore, efforts to enhance educational experiences and academic outcomes of students with learning diffi- culties are crucial for strengthening the capacity of schools to serve equitably all learners. The current biopsychosocial model for understanding disability (WHO 2001, 2007) has the potential to provide significant clues for improving professional practices aimed to increase students' meaningful participation in school settings and activities. Contrasting with impairment-based approaches, the biopsychosocial perspective describes disability not as a within-person defect but as the result of a mismatch between individuals' capa- bilities and the demands of the environment (Schalock et al. 2010; Thompson, Wehmeyer, and Hughes 2010). Thus, rather than concentrate educational efforts on remediating student deficiencies, intervention strategies consistent with biopsychosocial assumptions consider that environmental accommodations are a critical factor for enhancing academic 
involvement and learning of children with disabilities (Simeonsson, Simeonsson, and Hol- lenweger 2008). In this vein, the evaluation of how environmental arrangements might be modified to reduce the gap between students' levels of performance and the demands from educational contexts is conceived as a basic requirement to define the supports and ser- vices needed by those students. As such, in the field of special education, several efforts have been made to replace disability classifications or categorical systems - i.e. taxonomies based on clinical diagnoses or on the severity of impairments - by multidimensional and functional approaches, in which the emphasis is placed on students' participation as a result of the interaction between environmental and biological factors (Norwich 2008).

\section{The use of the ICF-CY: a multidimensional approach to education}

The International Classification of Functioning, Disability and Health for Children and Youth (ICF-CY) (WHO 2007), recognised as a multidimensional and functional-oriented framework, has been discussed as a promising tool to support the definition of eligibility criteria and the collection of information required for the organisation of assessment and intervention processes underlying special education responses (Hollenweger 2011). The ICF-CY brings up a framework reflecting the move from impairment-based approaches to context-sensitive ones. It embodies a biopsychosocial perspective of disability by con- sidering: (1) the role of both biological and environmental factors in shaping individuals' functionality and disablement processes; (2) the reciprocal relationships existing between the individual and environmental characteristics; and (3) the use of a neutral language supporting not only the description of disability (i.e. negative interactions between per- sonal and environmental characteristics), but also the portrayal of functioning (i.e. positive interactions between personal and environmental characteristics) (WHO 2007). The ICFCY provides a taxonomic structure for the description of human functionality organised into four main interactive components: Body Functions, Body Structures, Activity and Participation, and Environmental Factors (Figure 1).

Each component is represented by letters (b - Body Functions; s Structures; $d$ - Activities and Participation; e - Environmental Factors) and 
includes a list of numerical codes assigned to neutral definitions. After collecting information about each code, the

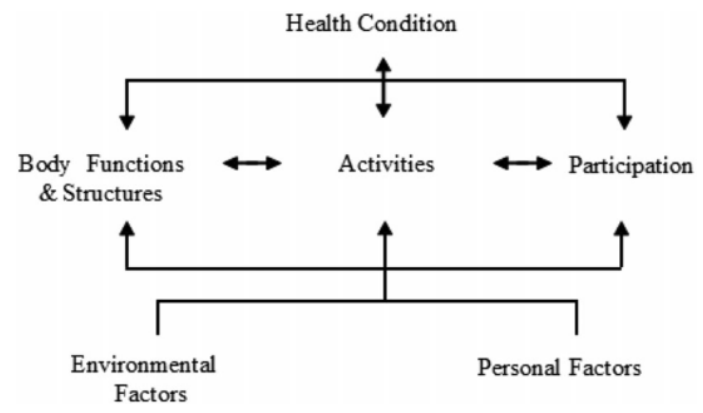

Figure 1. ICF-CY model (2001, 2007).

functioning profile must be completed ascribing qualifiers which describing the magni- tude of impairments in Body Functions and Structures and of limitations/restrictions in Activities and Participation components. Using the ICF-CY for describing students' func- tional profiles involves the assignment of ratings (qualifiers) to relevant codes with the purpose of estimating the magnitude of impairments in Body Functions and Body Struc- tures, and the degree of limitations or restrictions in Activities and Participation. With regard to the Environmental Factors, qualifiers represent the extent to which a factor acts as facilitator or barrier for the students' functioning. Qualifiers range in a $0-4$ scale $(0=$ no problem; $1=$ mild problem; $2=$ moderate problem; $3=$ severe problem and $4=$ complete problem). The description of Environmental Factors is based on the same scale, using a plus sign to describe when they are facilitators.

In order to capture the complex multidimensionality of the student's functioning, codes related to each component should entail a narrative of performance portraying how Activities and Participation are affected by interactions between Body Functions, Body Structures and Environmental Factors. The ICF-CY considers two constructs when assigning qualifiers to the Activities and Participation component: capacity - 'describing an individual's ability to execute a task or an action in a uniform or standard environ- ment'; and (2) performance - 'describing what an individual does in his or her current environment' (WHO 2007). An eventual gap between capacity and performance provides useful information about what needs 
to be done in the individual's environment to improve performance. For both constructs, the ICF-CY contemplates the possibility of describing capacity and performance either with or without assistance so that the best environmental arrangements aimed at increasing students' involvement might be explored. For example, the current difficulties of a student in solving problems can be described as a limitation due to memory impairments and the length of activities. Then, the impact of such limitation on problem-solving may decrease when specific changes of the environmental conditions are implemented (e.g. using as strategy the seg- mentation of activities).

\section{Portuguese scene of special education policy}

Consistent with current international efforts to promote inclusion and implement a functional approach for understanding disability (Hollenweger 2011), Portugal enacted in 2008 a new special education law - Public Law No. 3/2008, which introduced

several changes in assessment and eligibility processes. As defined by this Law, the target group for special education services comprehends those students with 'significant limit- ations in terms of activity and participation in one or more areas in life due to perma- nent functional and structural issues, which result in continued difficulty in terms of communication, learning, mobility, autonomy, interpersonal relationships and social involvement' ( $\mathrm{PL}$ 3/2008, official translation in European Agency for Development in Special Needs Education 2009). Moreover, the Portuguese Law states that, in the scope of special education services, the assessment process for eligibility and interven- tion planning should be conducted by an interdisciplinary team with reference to the ICF-CY framework. The assessment process results in the description of a functioning profile, which serves as the basis for the decision-making about the student's eligibility for special education services. This means that the eligibility for special education ser- vices depends on functioning profiles rather than on diagnostic categories and/or impairments. When a student is suspected to have special needs, the school principal requests an initial evaluation to appraise whether a specialised assessment is justified or not. If concerns about the student's difficulties are substantiated in such 
evaluation, the principal requires the establishment of an interdisciplinary team to assess the stu- dent's needs. The team includes the child's parents, as well as the regular and special education teachers. If necessary, it may also include experts from specific fields (e.g. psychologists, therapists) as well as other professionals from existing local services (health services and specialised resource centres), together with the parents and teachers. The assessment process proceeds through the identification of the ICF-CY that should be assessed and with decisions regarding which methods and tools the information is to be gathered with. This process yields the student's functioning profile in which his or her involvement in different domains of Activity and Participation is described as a result of the dynamic interactions between Body Functions, Body Structures and Environmental Factors. It is on the understanding of such dynamic interactions that educational responses are designed and included in the student's Individualized Edu- cation Program (IEP).

\section{The need for training on using the ICF-CY framework}

As a consequence of changes introduced by the Law No. 3/2008 and its impact on pro- fessionals' practices, a number of studies have been conducted aimed at analysing the use of ICF-CY in special education assessment and eligibility processes. One of these studies explored, through a focus group, the perceived advantages and disadvantages of using the ICF-CY, as well as the challenges and difficulties faced in using it (Sanches-Fer- reira, Silveira-Maia, and Alves 2014). Results from a nationally representative sample revealed that the use of the ICF-CY was acknowledged as a significant contribution to gen- erate richer descriptions of students' functioning. However, professionals also identified challenges, namely on: (1) measuring the extent of problems and, consequently, assigning qualifiers to ICF-CY codes; and (2) selecting the most appropriate set of codes to describe students' functioning, especially within the Body Functions component. Professionals emphasised training on the use of the ICF-CY as the key support for properly implement- ing the ICF-CY framework and terminology. 
In another study consisting of a documental analysis over a nationally representative sample of functioning profiles (Sanches-Ferreira et al. 2013, 2015), results showed that while the ICF-CY taxonomy was being formally used (evidenced by the use of codes), its conceptual framework was not fully implemented, that is, the codes were applied sep- arately without documenting reciprocal influences between them. Specifically, the impact of environmental factors on students' performance was commonly disregarded on the examined processes. This tendency was also observed in other studies evidencing an inci- pient linkage between environmental factors and students' performance (Silveira-Maia, Lopes-dos-Santos, and Sanches-Ferreira 2016).

These results highlight the importance of training the teachers in the planning and reasoning over assessments, and were the foundation for conceiving and implementing an in-service teachers' training (INSET) on the use of the ICF-CY.

\section{Teacher professional development: lifelong learning and innovation}

The ICF-CY implementation, as representing an innovative approach involving new sets of skills and knowledge, highlighted the importance of teachers' lifelong education on dealing with a new spectrum of challenges. Indeed, as any other new set of skills and knowledge, the use of the ICFCY must be accompanied by concomitant professional development (Greenhalgh et al. 2004). However, in practice, the introduction of the ICF-CY in the Portuguese educational system reflected a top-down policy, in the sense that most adopters were not provided with the reasoning supporting the new policy. Such process has been described as a factor for markedly enhancing the chance of failure (Collinson et al. 2009). As noted by Ketelaar et al. (2012), training and knowledge are of fundamental importance in supporting the accommodation of professionals' frame of reference to meet the situational demands of innovations. Consequently, teachers with training and knowledge are more likely to successfully adopt the changes introduced by educational reforms.

The success of teacher training has been described as more effective when it: (1) attends to teachers' own experiences, which means promoting experiential learning; (2) gives teachers the opportunities for 
'hands-on' work, promoting active learning; and (3) is aligned with teachers' goals and daily life at school, being compatible with other learning activities (Garet et al. 2001). Ofsted (2001) also outlines the importance of providing, during teacher training, opportunities for discussions and for the sharing of ideas among professionals. Within this context, self-reflection and shared reflection is a core tool for teacher training effectiveness (Belvis et al. 2013). By applying a reflective practice, teachers reframe and deepen their understanding of their role as well as evalu- ate the effects of their own practice (Hatton and Smith 1995). For that, field experiences can be used to promote a link between what is being taught and how it could be used in practice, facilitating the adoption of training contents on a permanent basis (Darling- Hammond 2006).

Further to these key predictors, several authors point out the importance of a set of strategies, including: the use of cases and experiences reported by teachers in order to demonstrate the implementation of the new knowledge (Hockly 2000); the 'thinking aloud' used to explain the reasoning that allows teachers to produce strategies and solve problematic situations (Short et al. 1991); the promotion of opportunities to practice acquired skills (Muijs and Reynolds 2001); and the continuous support and feedback for teachers (Joyce and Showers 1988).

Across the world, several countries have been developing initiatives to improve ICF-CY- related knowledge and coding skills, providing training programmes for professionals from different areas. South Africa (Reed et al. 2008) and Italy (Battaglia et al. 2004) are just some examples. The empirical research about the effects of these training programmes shows that teachers come away from training with improvements in conceptual and procedural knowl- edge and a more positive attitude towards the ICF-CY framework (Reed et al. 2008).

Inscribed in the context of a Portuguese policy reform that introduced the ICF-CY as a framework to guide the assessment and eligibility for special education services, this study aimed to evaluate the effects of an INSET on teachers' skills to use the ICF-CY conceptual framework for describing students' functioning. Specifically, we sought to evaluate changes in descriptions of students' functional characteristics by comparing functioning profiles designed before and after the INSET course. The research question that guided the study was: how different are functioning profiles 
described before and after the INSET in terms of: (a) broadness and multidimensionality of the descriptions regarding each ICF-CY component; (b) comprehensiveness of the descriptions - portraying inter- relations between students' Activities and Participation and Environmental Factors; and (c) documentation of students' strengths.

\section{Method}

\section{Sample}

The INSET entailed 6 editions and was attended by 118 regular and special education tea- chers from different schools in the Porto district, who applied by their own initiative to the training. None of the attendants had ever had training in using the ICF-CY. Regular and special education teachers were asked to provide a functioning profile from a selected student. At the end of the INSET, course teachers were asked to provide a revised func- tioning profile written for the same student. Therefore, 236 functioning profiles written for 118 students with additional support needs were examined. The students considered on the profiles were mainly from the 1st cycle, between $1 \mathrm{st}$ and 4 th grades (41.1\%); being the target of educational measures that mostly included curriculum accommo- dations (62\%). Their clinical diagnosis included a wide spectrum of conditions such as cer- ebral palsy (11.9\%), developmental delay (13.6\%), autism (13.6\%) and intellectual disability (13.6\%).

\section{INSET course}

The INSET course named 'Designing Individualized Educational Plans congruent with ICF-CY-based special needs assessment' was developed. The use of the ICF-CY framework for documenting students' functioning was a component of this broader training purposed at enhancing teachers' skills to develop IEP.

Regarding learning outcomes at the end of this INSET, course trainees were expected to be able to acknowledge the biopsychosocial perspective on the description of the function- ing profiles of students in need of special education services, specifically: 
(1) To understand disability and functioning experiences from a biopsychosocial perspective;

(2) To adopt a multidimensional approach to students' functioning identifying and documenting relevant biological (i.e. body functions and structures), psychological (activities and participation) and social (environmental factors) dimensions of func- tioning and disability experiences;

(3) To capture the dynamic interactions between the individual and environmental factors; explaining students' participation with and without assistance;

(4) To portray what students can do, rather than what they can't.

To achieve these learning outcomes, a problem-solving approach searching for which body functions and environmental factors explain activity and participation limitations/ restrictions (Björck-Åkesson, Granlund, and Olsson 1996) - was used as the core of this training.

The INSET course consisted of 25 hours structured in six group-sessions of four hours (with the exception of the last one, which took five hours). In order to evaluate the INSET effects, teachers were asked in the first group session to select a student with additional support needs with whom they used to work. All the INSET course materials were pro- duced for this real student.

Supporting an active and constructivist learning, the emphasis of the INSET course was placed on a scaffolding strategy consisting of a set of instructional techniques used to move teachers progressively to a deeper understanding and greater independence in the learning process, valuing their experiential learning (Alexander 2004). Such techniques included:

- Theoretical and practical demonstrations - each training session encompassed the presentation of the theory, followed by practical demonstrations where the trainer describes functioning profiles for each of a number of students, through cases brought by teachers, in which the trainer demonstrated the implementation process of the new knowledge. Cases were students selected by each teacher (e.g. teachers described the disability of the student in a specific domain 
and the trainer proceed to the exercise of identifying the student's main problem with regard to his/her per- formance of Activities and Participation, and how it could be explained by biological and environmental factors).

- Oriented practices - immediately after theoretical/practical demonstrations, teachers were provided with opportunities to practice their skills, conducting the problem- solving process on their own (e.g. teachers were asked to determine their students' main problems). 'Thinking aloud' strategies were used to explain the reasoning that allows teachers to produce strategies and solve problematic situations. Continuous support and feedback were provided to teachers.

- Autonomous practice - training sessions were separated by periods of implementation (one or two weeks), in which teachers could implement the INSET contents, incorpor- ating home assignments. This field experience was intended to promote a link between what was being taught and how it could be used in practice, in a manner that facilitates the adoption of the contents on a permanent basis. For instance, assessing during field experiences the capacity and performance of the student, with and without assistance, in order to identify the best environmental facilitator to support his/her participation.

- Reflection - each session started with the description of the field experience and tea- chers were asked to reflect on the applicability and effects of the contents and strategies taught.

From the start, teachers' ways of thinking and working are taken into account so that these techniques can be customised to the intended audience. All techniques were transversally used to achieve each learning outcome, as it is reflected on Table 1 concerning the training structure.

\section{Coding schema and data analysis}

To examine whether teachers improved their skills in describing functioning profiles of students, initial and final functioning profiles were compared through a documental analysis conducted by two researchers - authors of this study - who were not involved in the training. This analysis entailed 
two levels: (1) broadness and multidimensionality, meaning the extent that each ICF-CY component was referenced along the functioning profiles; (2) interrelatedness, concerning the extent to which the descriptions focused the mutual influences between ICF-CY components, specifically the environmental impact on students' Activity and Participation; and (3) emphasis on students' strengths through the description of what students can do.

First level - broadness and multidimensionality of the descriptions

In the first level, all codes embodying functioning profiles of students were registered and examined with regard to frequency and organisation. The count of ICF-CY codes adopted

Table 1. Overview of the INSET course in ICF-CY.

\begin{tabular}{ll}
\hline Session & Description \\
\hline 1stsession & Theoretical demonstration and Reflection - based on previous knowledge of learners and \\
the presented frameworks, materials and best practices about: conceptual models of disability \\
and intervention issues within the realms of a human rights agenda; the ICF multidimensional \\
structure and its interactive model; the use of a problem-solving method as a strategy to write \\
holistic FPs consistent with the person-environment fit approach. \\
Autonomous Practice: assignment to collect assessment information (in multidimensional terms \\
- about Body Functions/Structures, Activities and Participation and Environmental Factors) about \\
a selected case. \\
Practical Demonstration and Oriented Practices - modelling learners' practices in the \\
description of students' functioning profiles \\
2nd session \\
Demonstration of using a problem-solving model as the previous step for the design of \\
functioning profiles; \\
and Thinking aloud in identification of steps required to write a functioning profile (put \\
questions and strategies to solve them) and asking for the learners' active participation. \\
Autonomous Work: assignment to reorganise the assessment's information acknowledging mutual \\
influences established between ICF components. \\
Oriented practices and reflection - \\
Analysis of a case in small working groups (4/5 elements) with the aim to practice and generalise \\
3rd and 4th \\
sessions
\end{tabular}


the following procedures: (1) if the functioning profile included qualitative descriptions using the ICF-CY terminology, it was subjected to a manifest content analysis, as described by Graneheim and Lundman (2004), in which visible dimensions of functioning were registered. In this process, researchers registered ICF-CY codes included in functioning profiles: (2) if the functioning profile included qualitative descriptions without using the ICF-CY terminology, it was submitted to a latent content analysis applying the linking rules of Cieza et al. (2005) to guide the categorisation process. In this process, researchers identified meaningful concepts about students' functioning and matched to the most precise ICF-CY code.

Second level - interrelatedness of the descriptions In analysing the functioning profiles, we note whether the ICF-CY components are described separately - in a linear perspective - or if in a connected way - in an interrela- tional perspective (Table 2).

Furthermore, this level of analysis consisted of the examination of descriptions included in functioning profiles through a semantic analysis. The phrase was established as the unit of meaning, corresponding to a description of functioning. In this level of analysis, we examined whenever descriptions focused on Environmental Factors as explanations of the Activities and Participation component. This was considered when propositions men- tioning Activities and Participation were connected to Environmental Factors (e.g. 'with verbal clues from adults, the student can stay on a task until its completion'). To identify this connection, we took into consideration the use of connectives such as conjunctions, sentences adverbs and adverbial compounds (Dijk 1985).

\section{Third level - emphasis on students' strengths}

Descriptions reporting students' strengths were also taken into account. It was counted as a description of students' strengths whenever they were written in a positive way empha- sising what the student can do rather than in a negative way, emphasising what he can't do ('the student made prevocalizations in his interactions with others' instead of 'the student doesn't 
speak and doesn't interact with others').

Five randomly selected functioning profiles were independently codified by two researchers, who have a wide knowledge and training in the ICF-CY conceptual model and terminology, and specifically in the study of functioning profiles. The codification was then compared between both researchers to identify the number of similar codes

Table 2. ICF-CY codes organisation.

His colleagues act as moderate barriers (e325.2)

Functioning profile

Linear description of ICF components

Body functions

The student has moderate impairments in articulation functions (b320.2);

Activities and participation

He has severe difficulties in speaking (d330.3); He has moderate difficulties in interrelationships with other (d7204.2);

Functioning profile

Interactional description of ICF components

The student has moderate difficulties in interrelationships with others ( $d 7404.2)$ because he can't articulate $/ \mathrm{r} /$ (b320.2), which influence his capacity to speak (d330.3). On the other hand, his colleagues are not aware of this difficulty and don't try to understand him $(\mathrm{e} 325.2 \rightarrow \mathrm{d} 7404.2)$.

Environmental factors 
among total codes ascribed to the examined contents. The reliability of the analyses was certified by an inter-coder agreement above $95 \%$.

\section{Results}

Broadness and multidimensionality of the descriptions

Functioning profiles described before and after the INSET were examined in order to determine whether the course supported a broad and multidimensional approach to func- tioning. This first level of analysis concerned the ICF-CY codes within functioning pro- files. A total of 3693 $(M=31)$ codes made up the initial functioning profiles, whilst $3358(M=$ 28) codes were found in the final functioning profiles. Figure 2 displays the number of references allocated to each ICF-CY component on the functioning profiles written before the INSET course compared to those of the profiles written after. Compared to the initial ones, functioning profiles written after the INSET included significantly less references to Body Functions $(t(117)=2.643, p=.009)$. We also saw a decrease in Activi- ties and Participation references and an increase in Environmental Factors but they did not reflect a significant change.

Overall, the focus of functioning profiles remains on the Activities and Participation com- ponent - before and after the INSET - which is in agreement with the research project about the national evaluation of the Law No. 3/2008 implementation (Sanches-Ferreira et al. 2010). Concerning the way ICF-CY codes were organised within functioning profiles, differ- ences were registered, indicating teachers' efforts to operationalise the multidimensional perspective of functioning after the INSET course (Figure 3). In this context, $80.5 \%(n$

= 95) of functioning profiles designed after the INSET were structured in a dynamic per-

spective against the $9.3 \%(n=11)$ initial functioning profiles.

Although the multidimensional approach was already being implemented by teachers before the INSET, functioning profiles produced at the end of the course suggest that tea- chers were more able to reflect on the multidimensionality indicator of functioning under an interrelational perspective, as reflected in the ICF-CY conceptual model.

Furthermore, data suggest teachers' efforts to progressively replace the 
linear descrip- tion of the ICF-CY components with an interactive perspective.

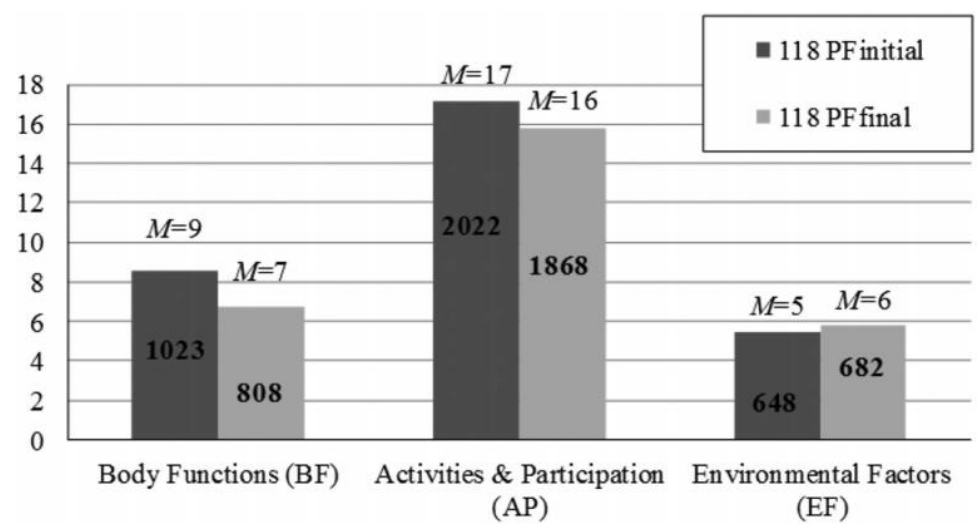

Figure 2. Codes distribution among the ICF-CY components (mean and frequency).

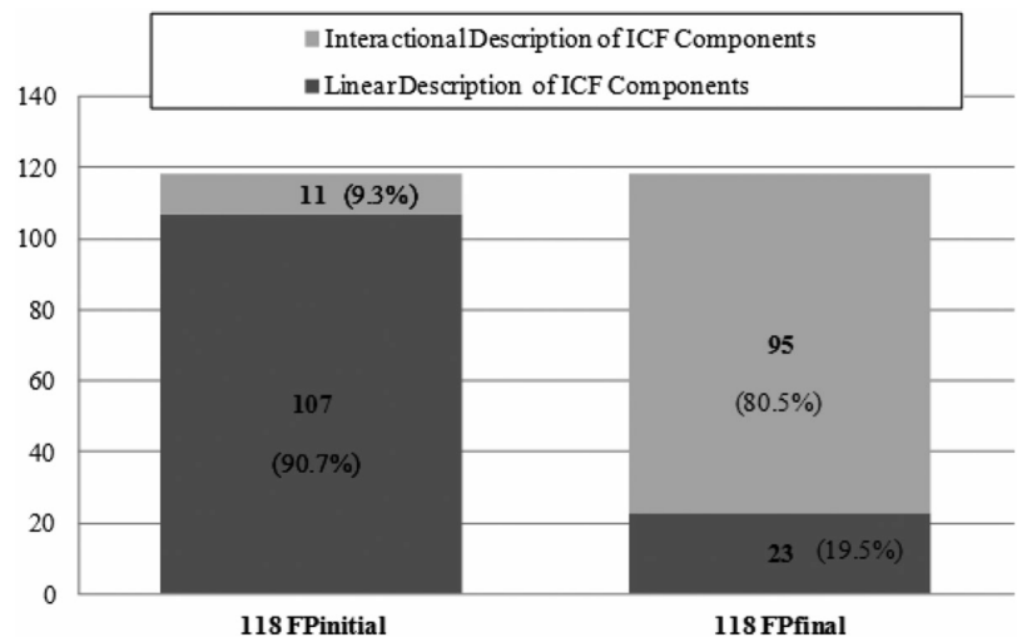

Figure 3. Structure of information within functioning profiles.

Interrelatedness of the descriptions

Regarding the second level of analysis, data revealed that final functioning profiles included significantly more qualitative descriptions than the ones written before the INSET course, $t(117)=-2.909, p=.004$. The passage from a total of $3847(M=33)$ descriptions in initial FP to $4552(M=39)$ in final FP suggests an increased need to docu- ment more comprehensive information beyond the ICF-CY codes.

Furthermore, the interrelation between Activities and Participation and 
Environmental Factors components was examined. Functioning profiles written after the INSET pre- sented a significant increase in references to Environmental Factors explaining the limit- ations and restrictions in Activities and Participation (Figure 4), $t(117)=-8.814, p<.001$. This means that final functioning profiles included significantly more statements reporting how the Environmental Factors were interfering with students' performance of Activi- ties and Participation. For example, while teachers used to write 'the student cańt walk', they now write 'given physical support, John can walk 3 steps'.

The increased number of descriptions of what the student can do with environmental supports represents the key outcome of this INSET. This suggests that teachers are more able to move from 'within-child' explanations of disability to a context-sensitive perspective. Reporting the personenvironment interaction implies that teachers assessed not only the students' performance but also the impact of Environmental Factors on his/her perform- ance. The acknowledgement of what environmental factors already support or hinder stu- dents' functioning gives nuclear indications for 'what needs to be done' and, consequently, establishes the baseline for the design of intervention strategies and goals.

\section{Emphasis on students' strengths}

With regard to references to students' strengths, a significant increase was observed after the INSET, $t(117)=-7.042, p<.001$ (Figure 5).

Teachers were more able to describe students, highlighting what they can do instead of presenting negative statements like: 'John can't walk'. This type of restrictive information provides teachers, parents and other educational professionals with limited material for 


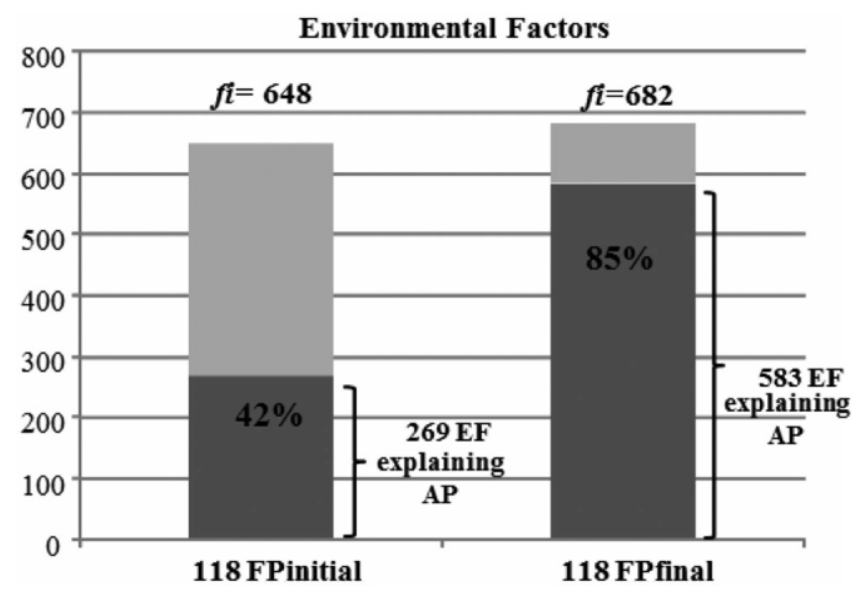

Figure 4. References to Environmental Factors as explanations of Activities and Participation in descrip- tions within functioning profiles.

intervention purposes. But if they know how John moves, 'John can crawl and can stand up in front of a table holding himself with his hands resting on the table', they can plan intervention strategies and goals from here.

\section{Discussion}

This study aimed to evaluate the effects of the INSET course on the use of the ICF-CY in educational contexts, specifically on teachers' skills for describing students' functioning. Training contents and strategies were developed, considering that the multidimen- sional and interactive understanding of human functioning reflected in the ICF-CY frame- work is the fundamental principle for its use in educational planning. As such, the teachers' ability to describe functioning profiles focused on understanding activities and participation as results of the interaction between body functions and environmental factors was the main expected outcome of this training. Such understanding seems crucial since it provides the conceptual basis for designing IEPs oriented towards the enablement of school environments. 


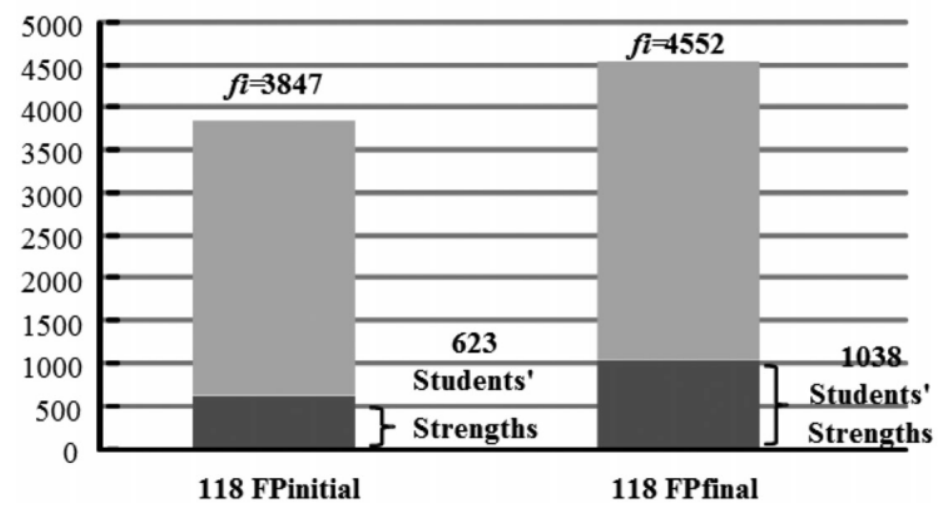

Figure 5. References to students' strengths within functioning profiles.

The analysis of data showed that the model adopted in the INSET course contributed to the enhancement of teachers' skills to describe functioning profiles of students reflecting the conceptual framework of the ICF-CY. Fundamental to this improvement was the use of a problem-solving approach, which helped teachers explain students' main problems in the Activities and Participation domain in terms of relationships between Body Functions and Environmental Factors. Adolfsson et al. (2010) also stressed the role of the ICF-CY in structuring problem-solving processes.

As previously explored, the biopsychosocial model contends that disability results from the interaction between the person and the environment. Aligned with such notion, func- tioning profiles designed after the INSET course entailed a higher number of references to environmental factors and to their role in explaining students' limitations and restrictions in Activities and Participation. As stressed by Hollenweger (2012), the contextualisation of students' performance considering, changing and verifying the impact of environmental circumstances over the child's participation is a guiding premise for an assessment process that truly informs the intervention planning. Indeed, if we understand inclusion as a process of contextenablement for better meeting students' needs, our results suggest that the INSET course was a step towards producing assessment outcomes more congruent with inclusion purposes.

Another crucial aspect was the building - after the INSET course - of more compre- hensive portrayals of students' characteristics revealed by 
the expansion of qualitative information about the specificity of each ICFCY code (i.e. what students do and how). Teachers also increased the attention provided to the description of students' strengths, documenting more often what the student does instead of what he or she is not able to do. As has been widely recognised, the emphasis on students' strengths is a fundamental requirement for basing effective interventions targeted towards the enhancement of stu- dents' participation (Terzi 2014). Based on the premise that the way a problem is described says a great deal about how it will be solved (Kirp 1982), changes introduced in teachers' views regarding the documentation of functioning profiles may support the development of more adequate interventions.

Overall, this paper raises a number of issues regarding the implementation of changes in teachers' daily practices. One of them is that knowledge and training - which are unquestionable requirements for operating any innovation - should be developed consid- ering teachers' understanding about the expected outcomes from such changes. Based on the analysis of the functioning profiles described before the training, results seem to evi- dence that the first understanding of teachers about the ICF-CY usage mainly consisted of merely codifying the assessment results, showing yet a segmented approach over students' functioning. In fact, the difficulties on capturing the mutual influences between ICF-CY components - and specifically, on assessing environmental influences on students' functioning - were already reported in previous studies (Sanches-Ferreira et al. 2013; Sanches- Ferreira, Silveira-Maia, and Alves 2014). The use of a problem-solving method provided a relevant basis to describe functioning profiles more compatible with multidimensional and interactional perspectives of human functioning and disability.

Some limitations need to be considered when interpreting the findings of this study. Data on the INSET course outcomes were collected immediately after its end. The conduc- tion of a follow-up evaluation would be important to determine whether teachers' skills to document interactional functioning profiles maintain after the training program. In fact, 
as stressed by Greenhalgh et al. (2004) - about the diffusion of innovations in service organisations - the main question concerns not the adoption of an innovation (or change), but its sustainability - i.e. the long-term adoption of the new set of procedures. Therefore, a clear limitation of this study was the absence of a follow-up that would inform to what extent the acquired skills were sustained and applied over time. Hence, future studies should attend to the provision of this INSET course to professionals belonging to the same school and evaluate the extent to which their skills improve and persist over time when all the educational community is involved in the same purpose.

The voluntary participation in this INSET course suggests, as stated by Opfer and Pedder (2011), that teachers may hold a positive perception of the learning activities pro- vided. However, even though teachers displayed a positive opinion about the INSET course (evident in the formal evaluation applied in all courses provided in the institution where this course was implemented, in which trainees report whether the course was compatible with personal expectations and goals), future replications should intentionally examine teachers' perception of its impact on improving the quality of their practices.

This study extends previous studies on training the ICF-CY use to support the docu- mentation of dynamic functioning profiles beyond merely applying the codes ratings. The challenge is now to extend the ICF-CY framework to intervention planning for a better congruence between assessment and intervention. The results of this study seem to contribute for further discussions on the use of a functioning-oriented approach to special needs assessment and eligibility decision-making.

\section{Disclosure statement}

No potential conflict of interest was reported by the authors.

\section{Notes on contributors}

Manuela Sanches-Ferreira, PhD, is Full Professor at the School of Education of Porto Polytechnic Institute. She coordinates the master programme in Special Education 
and is director of the Centre for Research and Innovation in Education (InED). Her research areas are concerned with the evalu- ation of inclusive policies and practices, intellectual disability and assessment of support needs.

Pedro Lopes-dos-Santos, PhD, is Full Professor of child development and education at the Univer- sity of Porto (Department of Psychology) in Portugal. His research focuses on the areas of children social emotional and social development, and evaluation of support needs for children with disabilities.

Silvia Alves, $\mathrm{PhD}$, is a research collaborator in the Centre for Research and Innovation in Education (InED), Porto Polytechnic Institute. Her research is concentrated in peers' attitudes towards the inclusion of children with disabilities, and the ICF-CYbased special needs assessment.

Mónica Silveira-Maia, PhD, is an invited adjunct professor of Special Education and Inclusion at the School of Education, Porto Polytechnic Institute. Over the last years, she has been contributing in several national and international research projects regarding disability and special education needs, namely on education inclusive policies and assessment procedures. 


\section{References}

Adolfsson, M., M. Granlund, E. Björck-Åkesson, N. Ibragimova, and M. Pless. 2010. 'Exploring Changes Over Time in Habilitation Professionals' Perceptions and Applications of the International Classification of Functioning, Disability and Health, Version for Children and Youth (ICF-CY)." Journal of Rehabilitation Medicine 42: 670-678. doi:10.2340/16501977-0586. Alexander, R. 2004. Towards Dialogic Teaching: Rethinking Classroom Talk. Cambridge: Dialogos

UK.

Battaglia, M., E. Russo, A. Bolla, A. Chiusso, S. Bertelli, A. Pellegri, G. Borri, and A. Martinuzzi. 2004. "International Classification of Functioning, Disability and Health in a Cohort of Children with Cognitive, Motor, and complex Disabilities." Developmental Medicine \& Child Neurology 46:98-106.

Belvis, E., P. Pineda, C. Armengol, and V. Moreno. 2013. "Evaluation of Reflective Practice in Teacher Education." European Journal of Teacher Education 36 (3): 279-292.

Björck-Åkesson, E., M. Granlund, and C. Olsson. 1996. "Collaborative Problem Solving in Communication Intervention." In Augmentative and Alternative Communication: European Perspectives, edited by S. von Tetzchner and M. Hygum Jensen, 324-341. London: Colin Whurr. Cieza, A., S. Geyh, S. Chatterji, N. Kostanjsek, B. Üstün, and G. Stucki. 2005. "ICF-CY Linking Rules: An Update Based on Lessons Learned." Journal of Rehabilitation Medicine 37 (2): 212218.

Collinson, V., E. Kozina, Y. K. Lin, L. Ling, I. Matheson, L. Newcombe, and I. Zogla. 2009. "Professional Development for Teachers: A World of Change." European Journal of Teacher Education32 (1):3-19.

Darling-Hammond, L. 2006. "Constructing 21st Century Teacher Education." Journal of Teacher Education57 (10):1-15.

Dijk, T. 1985. "Semantic Discourse Analysis." In Handbook of Discourse Analysis, vol. 2: Dimensions of Discourse, edited by T. A. van Dijk, 103-112. London: Academic Press.

EASNIE (European Agency for Special Needs and Inclusive Education). 2009. Identification of Special Educational Needs - Portugal. European Agency for Development in Special Needs Education. http://www.europeanagency.org/country-information/portugal/national-overview/ identification-ofspecial-educational-needs.

EASNIE (European Agency for Special Needs and Inclusive Education). 2011. Participation in Inclusive Education - A Framework for Developing Indicators. Odense: European Agency for Special Needs and Inclusive Education. 
Garet, M., A. Porter, L. Desimone, B. Birman, and K. Yoon. 2001. "What Makes

Professional Development Effective? Results From a National Sample of Teachers." American Educational Research Journal 38 (4): 915-945.

Graneheim, U., and B. Lundman. 2004. "Qualitative Content Analysis in Nursing Research: Concepts, Procedures and Measures to Achieve Trustworthiness." Nurse Education Today 24 (2): 105-112.

Greenhalgh, T., G. Robert, F. Macfarlane, P. Bate, and O. Kyriakidou. 2004. "Diffusion of Innovations in Service Organizations: Systematic Review and Recommendations." The Milbank Quarterly 82 (4): 581-629.

Hatton, N., and D. Smith. 1995. "Reflection in Teacher Education: Towards Definition and Implementation." Teaching and Teacher Education 11 (1): 33-49.

Hockly, N. 2000. "Modelling and 'Cognitive Apprenticeship' in Teacher Education." ELT Journal 54 (2): 118-125.

Hollenweger, J. 2011. "Development of an ICF-based Eligibility Procedure for Education in Switzerland." BMC Public Health 11 (4):1-8.

Hollenweger, J. 2012. "Developing a Unifying Language for Inclusive Education." Paper presented at the European Conference of Educational Research, Cádiz, Spain. http:/www.eera-ecer.de/ ecerprogrammes/conference/6/contribution/17735/

Joyce, B., and B. Showers. 1988. Student Achievement Through Staff Development. New York: Longman.

Ketelaar, E., D. Beijaard, H. P. A. Boshuizen, and P. J. Den Brok. 2012. “Teachers' Positioning Towards an Educational Innovation in the Light of Ownership, Sense-making and Agency." Teaching and Teacher Education 28 (2): 273-282.

Kirp, D. L. 1982. "Professionalization as a Policy Choice: British Special Education in Comparative Perspective." World Politics 34 (2):137-174.

Muijs, D., and D. Reynolds. 2001. Effective Teaching: Evidence and Practice. Gateshead: Athenaeum Press.

Norwich, B. 2008. "Perspectives and Purposes of Disability Classification Systems: Implications for Teachers and Curriculum." In Disability Classification in Education: Issues and Perspectives, edited by L. Florian and M. McLaughlin, 131-149. Thousand Oaks, CA: Corwin Press.

Ofsted. 2001. In-service Postgraduate Training Courses for Teachers: An Overview Report of Inspections of Courses Funded by the Teacher Training Agency. London: Office for Standards in Education.

Opfer, D., and D. Pedder. 2011. "Conceptualizing Teacher Professional Learning." Review of Educational Research 81 (3): 376-407. 
Reed, G. M., K. Dilfer, L. F. Bufka, M. J. Scherer, P. Kotzé, M. Tshivhase, and S. L. Stark. 2008. "Three Model Curricula for Teaching Clinicians to use the ICF." Disability and Rehabilitation 30 (12-13): 927-941.

Sanches-Ferreira, M. 2007. Educação Regular, Educação Especial - uma história de Separação.

Porto: Edições Afrontamento.

Sanches-Ferreira, M., M. Silveira-Maia, and S. Alves. 2014. "The use of the International Classification of Functioning, Disability and Health, Version for Children and Youth (ICF- CY), in Portuguese Special Education Assessment and Eligibility Procedures: the Professionals' Perceptions." European Journal of Special Needs Education 29 (3):327-343.

Sanches-Ferreira, M., R. J. Simeonsson, M. Silveira-Maia, and S. Alves. 2015. "Evaluating Implementation of the International Classification of Functioning, Disability and Health in Portugal's Special Education Law." International Journal of Inclusive Education 19 (5): 457- 468. doi:10.1080/13603116.2014.940067.

Sanches-Ferreira, M., R. J. Simeonsson, M. Silveira-Maia, S. Alves, A. Tavares, and S. Pinheiro. 2013. "Portugal's Special Education law: Implementing the International Classification of Functioning, Disability and Health in Policy and Practice." Disability \& Rehabilitation 35 (9- 10): 868-873.

Sanches-Ferreira, M., R. Simeonsson, M. Silveira-Maia, S. Pinheiro, A. Tavares, and S. Alves. 2010. Projecto de Avaliação Externa da Implementação do Decreto-Lei n. ${ }^{\circ}$ 3/2008. Lisboa: Direcção Geral de Inovação e Desenvolvimento Curricular.

Schalock, R., S. Borthwick-Duffy, V. Bradley, W. Buntix, D. Coulter, M. Craig, S. Gomez, et al. 2010. Intellectual Disability: Definition, Classification, and Systems of Supports. 11th ed. Washington, DC: American Association on Intellectual and Developmental Disabilities.

Short, E. J., S. W. Evans, S. E. Friebert, and C. W. Schatschneider. 1991. "Thinking Aloud During Problem Solving: Facilitation Effects." Learning and Individual Differences 3 (2): 109-122.

Silveira-Maia, M., P. Lopes-dos-Santos, and M. Sanches-Ferreira. 2016. "How the use of the International Classification of Functioning, Disability and Health for Children and Youth changed the Individualized Education Programs in Portugal." International Journal of Inclusive Education 21 (5): 573-583. doi:10.1080/13603116.2016.1218950.

Simeonsson, R., N. Simeonsson, and J. Hollenweger. 2008. "International Classification of Functioning, Disability and Health for Children and Youth: A Common Language for Special Education." In Disability Classification in Education: Issues and Perspectives, edited by L. Florian and M. McLaughlin, 207-217. Thousand Oaks, CA: Corwin Press.

Terzi, L. 2014. "Reframing Inclusive Education: Educational Equality as Capability Equality." 
Cambridge Journal of Education 44: 479-493.

Thompson, J., M. Wehmeyer, and C. Hughes. 2010. "Mind the Gap! Intellectual

Disability as Individual-Environment Fit: Implications for Students, Teachers, and Schools." Exceptionality: A Special Education Journal 18 (4): 168-181. doi:10.1080/09362835.2010.513919.

UNESCO (United Nations Educational, Scientific and Cultural Organization). 1994. "The Salamanca Statement and Framework for Action on Special Needs Education." World Conference on Special Needs Education. Salamanca, Spain: Access and Quality.

UN (United Nations). 1989. Convention on the Rights of the Child. New York: United Nations Office of the High Commissioner. http://www.ohchr.org/EN/Professionallnterest/Pages/CRC. aspx.

UN (United Nations). 2006. Convention on the Rights of Persons with Disabilities. New York: United Nations Division for Social Policy and Development. https://www.un.org/development/ desa/disabilities/convention-on-the-rights-ofpersons-with-disabilities.html.

WHO. 2001. International Classification of Functioning, Disability and Health (ICF). Geneva: WHO.

WHO. 2007. International Classification of Functioning, Disability and Health Version for Children and Youth (ICF-CY). Geneva: WHO.

WHO. 2011. World Report on Disability. Geneva: WHO. 